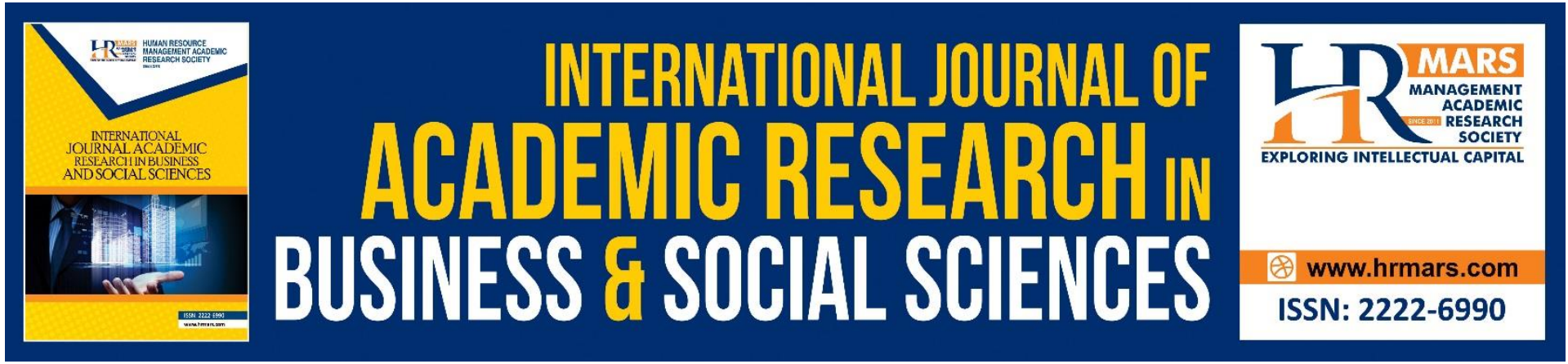

\title{
A Review on Vocabulary Learning Strategies Used in Learning English as A Second Language
}

Shangkari Jaikrishnan, Hanita Hanim Ismail

To Link this Article: http://dx.doi.org/10.6007/IJARBSS/v11-i9/10512

DOI:10.6007/IJARBSS/v11-i9/10512

Received: 06 July 2021, Revised: 30 July 2021, Accepted: 20 August 2021

Published Online: 12 September 2021

In-Text Citation: (Jaikrishnan \& Ismail, 2021)

To Cite this Article: Jaikrishnan, S., \& Ismail, H. H. (2021). A Review on Vocabulary Learning Strategies Used in Learning English as A Second Language. International Journal of Academic Research in Business and Social Sciences, 11(9), 297-309.

Copyright: (c) 2021 The Author(s)

Published by Human Resource Management Academic Research Society (www.hrmars.com)

This article is published under the Creative Commons Attribution (CC BY 4.0) license. Anyone may reproduce, distribute, translate and create derivative works of this article (for both commercial and non-commercial purposes), subject to full attribution to the original publication and authors. The full terms of this license may be seen at: http://creativecommons.org/licences/by/4.0/legalcode

Vol. 11, No. 9, 2021, Pg. 297 - 309

http://hrmars.com/index.php/pages/detail/IJARBSS

JOURNAL HOMEPAGE

Full Terms \& Conditions of access and use can be found at http://hrmars.com/index.php/pages/detail/publication-ethics 


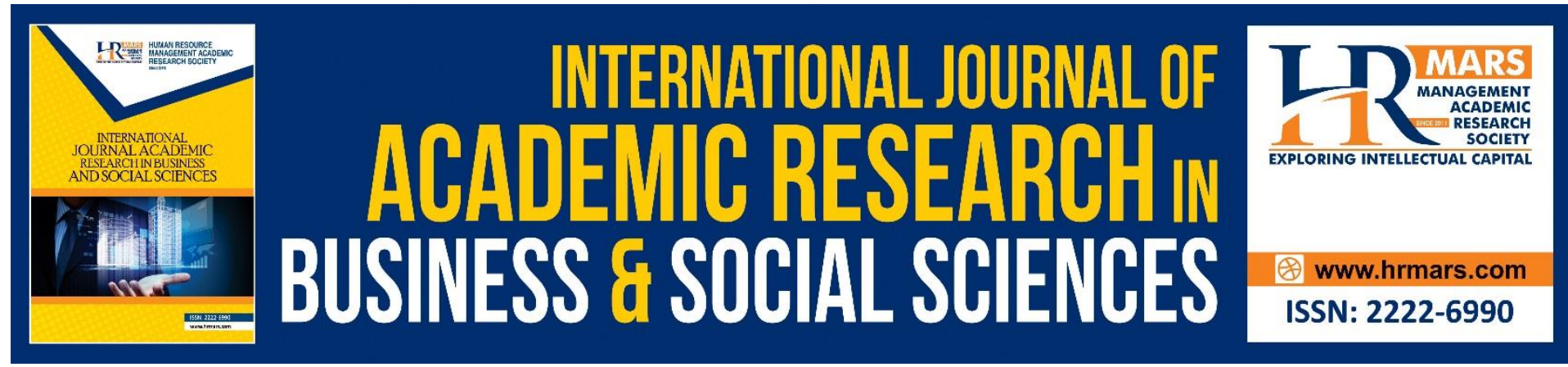

\title{
A Review on Vocabulary Learning Strategies Used in Learning English as A Second Language
}

\author{
Shangkari Jaikrishnan, Hanita Hanim Ismail \\ Faculty of Education, Universiti Kebangsaan Malaysia, 43600 Bangi, Malaysia
}

\begin{abstract}
This review aimed to analyse previous studies that analysed the use of vocabulary learning strategies (VLS) in learning English as a second language (ESL). The articles included in this review were chosen to understand and explore language learning strategies (LLS), definitions of LLS and its classifications, VLS, definitions of VLS, and its taxonomies, past studies on using VLS in learning ESL, and how good language learners are associated with the use of VLS. Past studies reviewed explored the use of VLS in both formal and informal context, and the learning of VLS both intentionally and incidentally. The findings showed that ESL learners' vocabulary was found to be greatly enhanced by the use of strategies, thus highlighting the significance of vocabulary for language proficiency. As for good language learners, they utilized VLS to further enhance their vocabulary acquisition. This review concluded by presenting several research gaps identified in the past studies. It was found that the use of VLS in learning ESL and by good ESL learners are less explored by researchers. Moreover, there seems to be a paucity of studies on training models of LLS. With this review, it is anticipated that future research could look into the identified research gaps and conduct research based on the use of VLS in learning ESL, the relationship between VLS and good language learners, and the effectiveness of training models of LLS that can also be used to train VLS to ESL learners.
\end{abstract}

Keywords: Language Learning Strategies, Vocabulary Learning Strategies, Incidental Vocabulary Learning, Intentional Vocabulary Learning, Good Language Learners

\section{Introduction}

Learning a second language is never an easy task. This includes the learning of English as a second language (ESL). Many challenges are faced by ESL learners; similar situations are also faced by learners who learn English as a foreign language. One of the major challenges faced by ESL learners is poor vocabulary which may lead to difficulties in learning their second language. New words and phrases can be difficult to be memorized and used while communicating. Nevertheless, these words and phrases are the ones that make up a language, and many researches have suggested that a learner's size of vocabulary is highly predictive of his language ability (Meara \& Jones, 1987; as cited in Gu, 1994).

The definition of vocabulary can be as simple as words of a language (LessardClouston, 2013), which is true as vocabulary deals with words. Lexis, a Greek term for word, is defined in English as "all the words in a language, the entire vocabulary of a language" 
(Barcroft, Sunderman \& Schmitt, 2011, p.571, as cited in Lessard-Clouston, 2013). However, vocabulary also includes lexical chunks which are phrases made up of two or more words. Thus, vocabulary refers to words of a language that includes single lexical items as well as phrases or chunks of words that convey a particular meaning, just like individual words. This shows that learning a second language cannot be done without learning its vocabulary as lexical knowledge is important and a fundamental component of communicative language proficiency (Beglar \& Nation, 2013).

With its importance seen as being deeply rooted within the initial stages of language acquisition, many researchers, in the past decades, have become interested in studying about vocabulary learning in a second language (Ramos \& Dario, 2015). These studies have particularly focused on strategies employed by ESL learners to learn vocabulary. As mentioned earlier, ESL learners are required to overcome manifold challenges in learning English. One of the ways they use to overcome their challenges is by employing learning strategies. According to Chamot and Kupper (1989), learning strategies are techniques used by learners to understand, store, and remember any information and skills. Likewise, there are strategies that are specially employed by learners to help them learn and improve their vocabulary. Therefore, the aim of this review is to analyse previous studies that address vocabulary learning strategies used in learning English as a second language.

\section{Review of Literature}

The criterion with which this paper is organized is based on four main areas: (1) understanding LLS, its definitions and classifications by researchers, (2) understanding VLS, its definitions and taxonomies, (3) past studies on VLS in learning ESL vocabulary, and (4) good language learners in the field of VLS.

\section{Understanding Language Learning Strategies}

Understanding what language learning strategies are and how they are related to vocabulary learning strategies is crucial. Language learning strategies (LLS) are sub-category of general learning strategies (Nation, 2001, as cited in Asgari \& Mustapha, 2012).

The early research on LLS emerged from studies that attempted to recognize characteristics of successful or good language learners (Hardan, 2013; Kölemen, 2021). The assumption was that if the characteristics of good language learners can be differentiated from the less successful learners, the performance of the latter ones can be enhanced and learning can be facilitated (Stern, 1975; Rubin, 1975, as cited in Kölemen, 2021). These studies eventually created the path for LLS research.

Many scholars have defined LLS based on the way learners manage the information received and the kind of strategies employed. Rigney (1987) defines LLS as the steps used by or behaviours of learners, often done consciously, to acquire, store, retain, recall, and use information better. Similarly, Oxford and Crookall (1989) state that LLS are strategies such as actions, behaviours, steps, or techniques used in enhancing and facilitation acquisition of language. Rubin (1987), as cited in Hardan (2013), on the other hand, defines LLS as behaviours, steps, or techniques employed by learners to ease language learning. Last but not least, Ghani (2003) defines LLS as specific actions, behaviours, steps, or techniques that are frequently used by learners to internalize, store, retrieve, or use new language which can enhance their progress in developing second language skills.

Oxford's (1990) definition of LLS also includes conscious and specific actions, behaviours, steps, or techniques used by learners to enhance their apprehension, 
internalization, and use of the second language. She then proceeds to classify LLS into two main classes, namely, direct and indirect strategies, going beyond and more in detail than the other classifications. The reason why Oxford's classification of LLS is more focused on here is it has been described as one of the most dominant classifications in the literature (PsaltaouJoycey \& Gavriilidou, 2015). Under each class, there are three subgroups. Direct strategies consist of memory, cognitive and compensation strategies while indirect strategies consist of metacognitive, affective and social strategies. Figure 1 presents Oxford's classification of LLS.

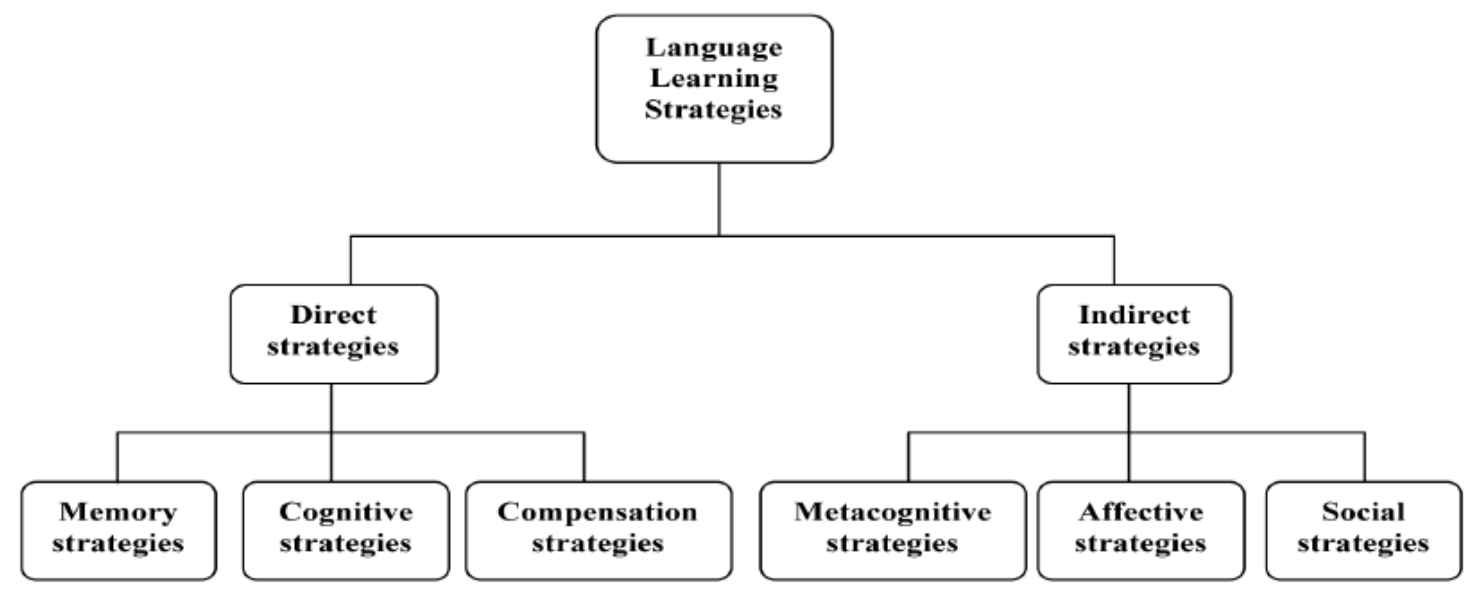

Figure 1: Oxford's (1990) Classification of LLS. Source: Asgari and Mustapha (2012)

\section{Understanding Vocabulary Learning Strategies}

Vocabulary learning strategies (VLS) are regarded as a part or a subclass of LLS (Nation, 2001, as cited in Asgari \& Mustapha, 2012; Rabadi, 2016). These are strategies which are employed by second language learners specifically to acquire new words and phrases in a second language. Thus, the definition of VLS is developed from LLS (Catalán, 2003; as cited in Rabadi, 2016).

VLS include any activities, techniques, methods, or ideas used by language learners to help them in acquiring, storing, retrieving, and using a language (Rubin, 1987; O'Malley \& Chamot, 1995, as cited in Rabadi, 2016). Cameron (2001), on the other hand, defines VLS as learners' actions to help themselves comprehend and remember vocabulary items. According to Schmitt (1997), as cited in Rabadi, 2016, "use" is seen as a vocabulary practice, so he regards anything that affect this practice as a vocabulary learning strategy. There are many classifications of VLS, proposed by different scholars, that demonstrate a wide range of strategies to acquire vocabulary (Stoffer, 1995; Gu \& Johnson, 1996; Schmitt, 1997; Nation, 2001).

Stoffer's (1995) taxonomy consists of nine main groupings with a total of 53 strategies which include strategies for authentic language use, creative activities, self-motivation, creating mental linkages, visual and auditory, physical action, overcoming anxiety, and organizing word. Gu and Johnson (1996) came up with another classification that consists of eight main groups of strategies which are for beliefs about vocabulary learning, metacognitive regulation, guessing, dictionary, note-taking, rehearsal, encoding, and activation. Nation's (2001) taxonomy uses three general classes, namely, planning, sources, and process to distinguish aspects of vocabulary knowledge and the learning process.

Among all, the most comprehensive and most frequently adopted taxonomy would be the one proposed by Schmitt (Catalan, 2003; Rabadi, 2016). Schmitt's taxonomy is based on Oxford's classification of LLS whereby he has included social, memory, cognitive and 
metacognitive strategies established by Oxford (1990), and invented a new category which is determination strategies. Furthermore, Schmitt (1997) has classified the strategies under two main groups which are discovery and consolidation strategies. Figure 2 illustrates the taxonomy by Schmitt (1997).

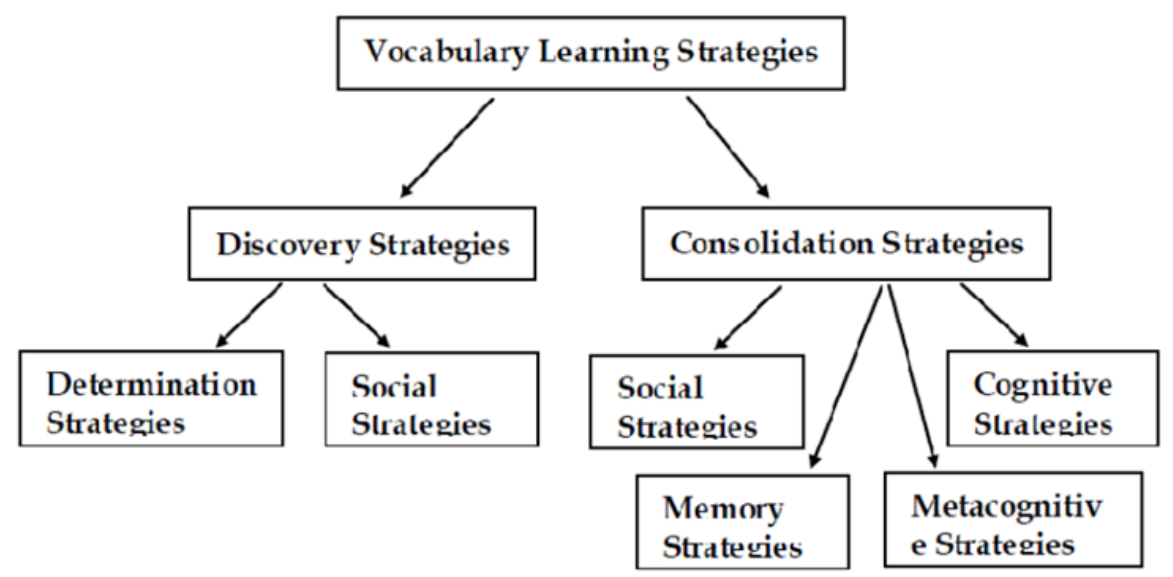

Figure 2: Schmitt's Taxonomy of Vocabulary Learning Strategies (1997). Source: Tanyer \& Ozturk (2014)

According to Schmitt (1997), discovery strategies are strategies used to discover new words. Under this group, there are two subcategories which are: (a) determination strategies, used by learners to discover the meaning of a new word without any additional help, and (b) social strategies, used to learn words through interactions with others. On the other hand, consolidation strategies, the second main group in this taxonomy, are strategies used to remember the meaning and other aspects of a newly learned word's lexical knowledge. Under this group, there are four subcategories which are: (a) social strategies, (b) memory strategies, used to link new words to one's prior knowledge, (c) cognitive strategies, mechanical means to memorize new words, and (d) metacognitive strategies, mental processes that involve planning, monitoring and evaluating one's learning.

\section{Past Studies on Vocabulary Learning Strategies Used in Learning English as a Second Language Vocabulary}

In this part of the review, to gain an understanding on the relationship between the use of VLS and learning English as a second language, topic search query phrases "Vocabulary Learning Strategies" and "Vocabulary Learning Strategies in ESL" were chosen. Other phrases, "Incidental and Intentional Learning of Vocabulary", "Self-regulated Learning, "Vocabulary", and "Technology", were also used to expand the search for past studies on VLS in ESL. Some concepts used as search queries are also explained in this section. Articles with even one relevant keyword are included. No country limit was set, but only studies conducted on learning English as a second language are taken. Other than that, articles published between 2012 and 2021 were chosen to be reviewed in this part of the paper.

Asgari and Mustapha (2012) studied VLS used by Malaysian undergraduate students, majoring in Teaching English as a Second Language (TESL). The researchers set out to investigate the use of VLS by Malaysian students at university level as well as the methods applied by them to learn new English words. This research employed a qualitative research design. An interview session was conducted individually with eight students, and open-ended questions were asked to them to achieve a profound understanding of their varied 
backgrounds in vocabulary learning as well as the strategies they use to learn new English words. The results showed that the participants most commonly used determination, cognitive, social as well as metacognitive strategies. For example, they use monolingual dictionary, guess the meaning from the textual contexts, and learn through English language media as well as reading materials. However, the findings of this study showed that the participants used VLS that are mostly direct and only require low mental processing.

Another study investigating the use of VLS was developed by Mokthar, Rawian, Yahaya and Abdullah (2017). This empirical study included 360 first- and second-year diploma students, chosen from a population of 5413 diploma students. Gu and Johnson's (1996) vocabulary learning questionnaire were administered to the respondents to identify VLS preferred by university students. The findings showed that guessing and dictionary strategies were the most preferred strategies while the other five strategies, namely, metacognitive regulation, note-taking, rehearsal, encoding, and activation, were less preferred by the respondents. Guessing and dictionary strategies are more of a direct strategy which represents normal functioning of individuals, a lower-level metal processing. However, Gu and Johnson's (1996) questionnaire consist of eight parts, including beliefs about vocabulary learning, but in Mokthar et al (2017), explanation was not given as to why this part was omitted in the adapted questionnaire.

Ali, Mukundan, Baki and Ayud (2012) investigated students' learning attitudes towards three vocabulary learning methods which are contextual clues, dictionary strategy and Computer Assisted Language Learning (CALL). This study involved 123 undergraduate students who were required to answer a survey questionnaire. The questionnaire was administered to identify the factors that affect the participants' attitudes in using the three aforementioned methods in learning vocabulary. The findings revealed that the students showed more positive attitude towards learning vocabulary using CALL, as compared to the other two methods, which could be due to the fact that the tools suited their learning aptitude. Using CALL, learners can engage in interactive learning of vocabulary using multiple hypermedia-based programmes, unlike the traditional method of vocabulary learning (Kukulska-Hulme, 1998). Nonetheless, the researchers recommended the integration of all three methods by teachers in their teaching to enhance students' vocabulary expansion.

In an article by Nisbet and Austin (2013), the use of mobile technology in enhancing ESL vocabulary development was discussed about. It is stated that adult ESL learners should make use of technologies such as applications on smart phones or tablets to develop their vocabulary and past studies on the benefits of technology use in ESL vocabulary development are cited. Not only that, useful vocabulary applications are also presented and discussed that can be useful for vocabulary teaching and learning. These applications are said to provide authentic use of language and knowledge on word-learning strategies such as using contextual clues and analysing word parts. This reflects the findings in Ali et al. (2012) that stated that technology such as CALL promoted positive impacts on students' vocabulary.

Bytheway $(2011 ; 2015$ a) conducted a qualitative study to explore English language learners' autonomy in learning vocabulary while playing Massively Multiplayer Online Roleplaying Games (MMORPGs), online role-playing video games in which a very large number of people participate at the same time. In this study, six experienced ESL players of World of Warcraft were selected and data were collected using semi-structured interviews, observation, elicited email texts and extant texts. The findings revealed that the participants employed 15 VLS such as selecting words for attention, using words to learn words, and receiving explanations and feedbacks. Many of the strategies identified could be classified 
into some of the existing taxonomies by other researchers (Schmitt, 1997). This shows that VLS can also be utilized in such an informal context that presents ESL learners a need to learn vocabulary as well as the ways to learn vocabulary autonomously. Moreover, putting together all the 15 VLS provided future researchers a framework to further study on VLS taxonomies.

\section{Incidental and Intentional Vocabulary Learning}

How do learners learn words? Deliberately or accidentally? Two common vocabulary teaching and learning strategies that must be addressed here are intentional (deliberate and conscious learning of words) and incidental (accidental and subconscious learning of words) vocabulary learning strategies; however, these two are considered highly controversial and still need to be investigated further. Both incidental and intentional vocabulary learning incorporate VLS discussed in the previous subheading, such as using dictionary (Gu \& Johnson, 1996), authentic materials (Stoffer, 1995), and social interactions (Schmitt, 1997). Intentional vocabulary learning is a method of learning in which the learner is well-informed and is aware of what he or she is going to learn (Karami \& Bowles, 2019). Some examples of intentional VLS are using word cards, keeping notebooks for vocabulary, writing word-lists, and memorization strategies (Elgort \& Nation, 2010; Hung, 2015). Incidental vocabulary learning, on the other hand, looks into acquiring words incidentally by means of meaningful contexts such as through interactions with others (Karami \& Bowles, 2019).

In a study conducted by Ahmad (2012), the distinction between intentional and incidental vocabulary learning was explored. He set out to identify the impacts of intentional and incidental vocabulary learning on Saudi ESL learners' ability in comprehending, retaining and using new words in diverse situations. Two tests were given to 20 undergraduate students. The first test, Standard Confirmation Test, was given to determine whether there was similarity in vocabulary learning among all selected learners. The second test was done to identify any differences between learners' performance levels based on intentional and incidental vocabulary learning. The findings showed that the participants were elementary users of English, with just some prior knowledge of the said language, and they performed significantly better with incidental learning than intentional learning.

However, in another study by Meganathan, Yap, Paramasivam and Jalaluddin (2019), it was suggested that a combination of incidental and intentional vocabulary learning is more effective. In this study, 99 primary school students were chosen to investigate the effectiveness of incidental learning and intentional learning of vocabulary among young ESL learners. Stratified sampling was used and the participants were equally divided into three groups, one control group and two experimental groups. The first experimental group (identified as $E R$ ) received treatment which included extensive storybook reading (incidental learning) while the second experimental group (identified as $E R+$ ) received treatment which included extensive reading and enhancement activities on vocabulary (incidental and intentional). The control group was only given regular class activities. Vocabulary levels test (VLT) was given to all the participants to measure the difference among the three groups. The results showed a significant gain in $E R$ and $E R+$ groups' post-test and delayed post-test scores, with ER+ having higher means in both tests which shows that a combination of both intentional and incidental works better. As for the control group, no gain was recorded.

\section{Good Language Learners}

It is evident that VLS plays a vital role in vocabulary learning, and sufficient vocabulary knowledge can positively affect other language skills of a target language which are reading, 
writing, listening, and speaking. Besides that, vocabulary can be developed either intentionally or incidentally with the right use of strategies. Having said that, characteristics of a good language learner must be addressed. Many scholars have associated the use of language learning strategies (LLS) with good language learners. As mentioned before, Hardan (2013) and Köleman (2021) stated that scholars became interested in researching about LLS when they were attempting to identify a good language learner's characteristic. The findings of these studies could also be applied to show the relationship between VLS and good language learners as VLS is a subcategory of LLS. Apart from studies that have investigated the use of vocabulary learning strategies by good language learners (Yaprak, Hayta \& Yaprak, 2013), there are also studies on LLS that look into strategies used by good language learners in learning vocabulary, along with other language skills.

A few characteristics are said to be possessed by good language learners (Rubin \& Thompson, 1994, as cited in Mahalingam \& Yunus, 2016). Firstly, they seek for opportunities on their own to use the language and take control of their own learning. This shows that good language learners are independent learners as they don't depend on others solely to learn a language and employ independent actions such as strategies to improve their learning. Secondly, they are not afraid of taking risks and perceive errors made as a guidance to enhance their learning. Next, they showcase creativity by experimenting with grammar and words. Not only that, good language learners, in learning a second language, showcase an ability to apply their linguistic knowledge, including knowledge of their first language or mother tongue.

In a study conducted by Mahalingam and Yunus (2016), LLS used by good language learners in learning ESL was investigated. A questionnaire was administered to 30 primary school pupils which good language ability. The findings showed that every pupil uses a variety of LLS to become a good language learner, and each pupil's choice of strategies differ from one another. However, there seem to be a few strategies that are common among good language learners. To improve their listening skills, the respondents stated that they ask people to repeat unfamiliar sounds and words. This can be linked with Oxford's (1990) social strategy. Social strategy is also found in Schmitt's (1997) taxonomy of VLS. Not only that, they also listed the use of dictionary as one of their most preferred strategies to improve their writing, which can be linked to Oxford's (1990) memory strategy as well as Gu and Johnson's (1996) taxonomy of VLS that identifies the use of dictionary as a strategy to learn vocabulary. In relation to vocabulary, the study by Mahalingam and Yunus (2016) found that good language learners prefer using rhyming to remember new words which resembles one of Oxford's (1990) indirect strategies which is lowering anxiety. A good language learner incorporates creativity and fun elements in his or her learning process to reduce anxiety. Similarly, in Stoffer's (1995) taxonomy of VLS, one of the strategies identified is overcoming anxiety.

In another study by Tigarajan, Yunus and Aziz (2016), focusing on identifying the highly preferred and the least preferred LLS to learn ESL, revealed that compensation and metacognitive strategies are the most preferred ones by good language learners, while their least preferred strategy is social strategy. In this study, 30 Form Four proficient students were chosen and a questionnaire was administered to them. The questionnaire, which looks into all the language skills, consisted of items adapted from Strategy Inventory for Language Learning (SILL) by Oxford (1989, as cited in Tigarajan, 2016) and Language Strategy Use Inventory by Cohen, Oxford and Chi (2005, as cited in Tigarajan, 2016). In relation to 
vocabulary learning, the most preferred strategy is memory strategy while the lest preferred strategy is affective strategy.

Similarly, in a study by Nazri, Yunus and Nazri (2016), the LLS used by 10 successful university ESL learners was investigated, using Oxford's (1990) Strategy Inventory for Language Learning (SILL). The findings revealed that the respondents used metacognitive strategies most frequently, followed respectively by compensation strategies, cognitive strategies, social strategies, memory strategies, and the least frequently used strategies were affective strategies (which corresponds with the study by Tigarajan et al., 2016). At the same time, the results also showed that the selected good language learners used and favoured more direct strategies over indirect strategies, which means they preferred using strategies that have direct impact on the target language and not necessarily the strategies that require higher levels of mental processing.

On the other hand, Alasmari (2019), VLS employed by good language learners were investigated. A case study was conducted with one 21-year-old student, chosen based on the student's high score in the Standardized Test of English proficiency (STEP). Three instruments were used to collect data, namely, a vocabulary size test to identify the student's vocabulary knowledge, vocabulary knowledge scale test to measure the student's vocabulary depth, and think-aloud protocol to observe the student's thoughts, reflections and views during the test. The findings of this study showed that the student employed a significant number of strategies, particularly two types of strategies which are metacognitive and cognitive. Though these two types of strategies are essential, they are not exclusive which means there are other strategies that can be used to learn vocabulary and be taught to less successful learners to improve their learning.

A rather contrasting finding was found in a study by Tılfarlıoğlu and Bozgeyik (2012). This study was conducted to identify second language learners' VLS and the relationship between the use of VLS and their vocabulary levels. 252 students of various proficiency were chosen and were given Vocabulary Learning Strategies Questionnaire (VLSQ) and Vocabulary Levels Test (VLT). The findings are as follows: (1) the participants used a variety of VLS, (2) general correlation results presented positive and important correlations between the VLS categories (particularly memory strategies) and VLT scores, and (3) correlation tests run for each proficiency group showed that language proficiency and vocabulary proficiency at different levels have an effect on the effectiveness of VLS. Therefore, there are some differences among the participants in terms of which specific VLS correlate with their vocabulary proficiency. However, the regression analysis results showed that none of the strategies predicted the participants' VLT scores.

Good language learners do demonstrate a wide use of strategies to enhance their language learning. Nevertheless, they do not necessarily use the same strategies or even use them in the same manner and for the same purpose (Tigarajan et al., 2016). There is a great number of studies done to show the relationship between LLS and good language learners. However, very few studies have focused on the use of VLS among good language learners (Alasmari, 2019).

\section{Discussion and Conclusion}

After reviewing the findings of this literature review, it has been identified that the use of VLS has an impact on second language learning. There are some strong evidences that show the use of VLS contributes positively in learning English as a second language. As such, many researchers have shown their interest towards studying the field of VLS. Nevertheless, 
it has also been found that there are more studies focusing on LLS than VLS. Even the ones that focus on VLS explored its use and effectiveness among English as a Foreign Language (EFL) learners, particularly tertiary and adult learners (Meganathan et al., 2019), and there are not many studies that looked into the use of VLS among ESL learners.

Not only that, the use of VLS is often associated with self-regulated or self-directed learning. Self-regulated learners are learners who do self-regulation, "the self-directive process by which learners transform their mental abilities into academic skills." (Zimmerman, 2002 , p. 65). A good self-regulated learner, among other things, demonstrates the use of effective strategies to achieve his or her goals (Zimmerman, 2008; Choi, Zhang, Lin \& Zhang, 2018). Nonetheless, very few studies have focused on investigating the use of VLS with selfregulated framework in the context of ESL. More attention is given on exploring the said concept in foreign language context. Could it be because EFL learners are not from an Englishspeaking country, therefore they are expected to be more self-directed in their learning as compared to ESL learners who live in an English-speaking country where there is said to be enough language input as well as opportunities for them to produce the target language (Choi et al., 2018)? But, how about ESL learners such as those in countries like Malaysia who struggle to become successful language learners despite years of schooling (Mahalingam \& Yunus, 2017), and may also tend to use such strategies to help them learn English? Thus, it is important for further research to also focus on investigating the use of VLS among good ESL learners to investigate its effectiveness as this could help ESL teachers and learners decide whether the use if strategies in language learning is beneficial.

Moving on, studies have shown that the use of VLS makes a difference between experienced and less experienced language learners. In fact, the notion of strategies is often associated with good language learners as they have been identified as ones who regulate their own learning by making use of suitable strategies (Rubin, 1975; Yaprak ey al., 2013; Hardan, 2013; Mahalingam \& Yunus, 2017; Nazri et al., 2016; Köleman, 2021). Rubin (1975), in researching about strategies of successful learners, stated that these strategies, once identified, can benefit the less successful learners. Hence, it is crucial for language teachers to identify those strategies used by good language learners and expose them to less successful learners who require more guidance and practice.

Conceptually speaking, Schmitt's taxonomy of VLS (1997) is the most frequently adopted taxonomy and is often cited by researchers and educators. However, there have been studies that looked into vocabulary learning in informal contexts, especially through online games such as MMORPGs (Bytheway, 2011), in which 15 VLS such as selecting words for attention, using words to learn words, receiving explanations and feedbacks, identifying gaps in knowledge, utilizing words to learn words, and using search engines were revealed. Many of the strategies identified could be classified into some of the existing taxonomies by other researchers (Gu \& Johnson, 1996; Schmitt, 1997). Nonetheless, there are not many studies that ventured into this taxonomy of VLS which actually provides a new framework for further study into VLS taxonomies as well as self-directed learning in informal digital contexts. Eventually, the strategies can be updated to mirror current learners' needs that have made computers and technology a part and parcel of their lives (Ali et al., 2012), and can also benefit teachers in identifying current strategies that their students can adopt and adapt to accelerate their language acquisition.

Other than that, language learners tend to differ in their choice of strategies to be used to achieve their desired language outcome. As pointed out by Asgari and Mustapha (2012), most strategies used by ESL language learners are common practices in learning ESL, 
so there are also some similarities in the use of VLS among ESL learners. However, learners seem to use strategies that require low mental processing, and more direct strategies such as cognitive strategies and guessing (Asgari \& Mustapha, 2012; Mahalingan \& Yunus, 2016; Mokthar et al., 2017). Since there is an emphasis on self-regulated learning as it reflects the characteristics of a good language learner, learners should be encouraged to employ indirect strategies such as metacognitive strategies as well (Nazri et al., 2016), that give them opportunities to activate higher order of cognitive processes.

It is hoped that this paper significantly provides an insight to educators on how language strategies work and their effectiveness, thus allowing them to comprehend the importance of introducing the strategies to their language learners, especially the ones who are considered less successful. Language teachers should expose their students to various strategies, and in order for them to do so, they must first equip themselves with the knowledge of strategies and learn how to train those strategies to their students. There are numerous training models of LLS that can help teachers in teaching their students how to apply the strategies in various language activities as well as to new situations in the language classroom and in areas that require language skills (Liu, 2010). However, this field is also less ventured upon by researchers as well, and that is why it requires more studies to be done to further develop and standardize it. Hence, this could be a great area future research could focus on, to study the applicability and effectiveness of the training models.

With proper guidance, practice and most importantly the educators' well-equipped knowledge on said strategies, these learners could climb the ladder of success in language learning much faster and better. Not only that, as mentioned earlier, there seems to be a dearth of studies on VLS, especially in the context of learning ESL as well as on the use of strategies among school students. Therefore, it is recommended that more future research could be undertaken on these areas to establish and reiterate the effectiveness of VLS in learning ESL, which can eventually add more to the existing knowledge on VLS and help ESL educators and learners of every level and institution.

\section{References}

Ahmad, J. (2012). Intentional vs. Incidental vocabulary learning. ELT Research Journal, 1(1), 71-79.

Alasmari, N. J. (2019). The Mind of a Good Language Learner: A Case Study of Vocabularylearning Strategies.

Ali, Z., Mukundan, J., Baki, R., \& Ayub, A. F. M. (2012). Second Language Learners' Attitudes towards the Methods of Learning Vocabulary. English Language Teaching, 5(4), 24-36.

Asgari, A., \& Mustapha, G. (2012). Vocabulary learning strategies of Malaysian ESL students. Pertanika Journal of Social Sciences \& Humanities, 20(3), 751-764.

Beglar, D., \& Nation, P. (2013). Assessing vocabulary. The Companion to Language Assessment, 1, 172-184.

Bytheway, J. A. (2011). Vocabulary learning strategies in massively multiplayer online roleplaying games.

Bytheway, J. (2015a). A taxonomy of vocabulary learning strategies used in massively multiplayer online role-playing games. Calico Journal, 32(3), 508-527.

Catalan, R. M. J. (2003). Sex differences in L2 vocabulary learning strategies. International Journal of Applied Linguistics, 13(1), 54-77. https://doi.org/10.1111/1473-4192.00037

Cameron, L. (2001). Children learning a foreign language. Lynne Cameron, Teaching Languages to Young Learners, 1-20. 
Choi, Y., Zhang, D., Lin, C.-H., \& Zhang, Y. (2018). Self-regulated learning of vocabulary in English as a Foreign Language.

Elgort, I., \& Nation, P. (2010). Vocabulary learning in a second language: Familiar answers to new questions. In Conceptualising 'learning' in applied linguistics (pp. 89-104). Springer.

Gu, Y. (1994). Vocabulary learning strategies of good and poor Chinese EFL learners.

Gu, Y., \& Johnson, R. (1996). Vocabulary Learning Strategies and Language Learning Outcomes. Language Learning Journal, s. 643-679.

Hardan, A. A. (2013). Language learning strategies: A general overview. Procedia-Social and Behavioral Sciences, 106, 1712-1726.

Hung, H.-T. (2015). Intentional vocabulary learning using digital flashcards. English Language Teaching, 8(10), 107-112.

Karami, A., \& Bowles, F. A. (2019). Which Strategy Promotes Retention? Intentional Vocabulary Learning, Incidental Vocabulary Learning, or a Mixture of Both? Australian Journal of Teacher Education, 44(9), 25-43.

Kölemen, Ü. (2021). A Systematic Review of Studies on Language Learning Strategies from 1977 to 2018. International Journal of Language and Literary Studies, 3(1), 151-169.

Kukulska-Hulme, A. (1988). A computerized interactive vocabulary development system for advanced learners. System, 16(2), 163-170.

Lessard-Clouston, M. (2013). Vocabulary and its importance in language learning. Teaching Vocabulary. http://www. Tesol. Org/Docs/Books/Bk_ELTD_Vocabulary_974.

Liu, J. (2010). Language Learning Strategies and Its Training Model. International Education Studies, 3(3), 5.

Mahalingam, K., \& Yunus, M. (2017). Good language learners and their strategies: An insight. Proceedings of the ICECRS, 1(1), 359-366.

Meara, P., \& Jones, G. (1987). Tests of vocabulary size in English as a foreign language. Polyglot, 8(1), 1-40.

Meganathan, P., Yap, N. T., Paramasivam, S., \& Jalaluddin, I. (2019). Incidental and intentional learning of vocabulary among young ESL learners. 3L: Language, Linguistics, Literature ${ }^{\circledR}$, 25(4).

Mokhtar, A. A., Rawian, R. M., Yahaya, M. F., Abdullah, A., \& Mohamed, A. R. (2017). Vocabulary learning strategies of adult ESL learners. The English Teacher, 12.

Nation, I. S. (2001). Learning vocabulary in another language. Cambridge: Cambridge University Press.

Nazri, N. M., Yunus, M. M., \& Nazri, N. D. M. (2016). Through the lens of good language learners: What are their strategies? Advances in Language and Literary Studies, 7(1), 195-202.

Nisbet, D., \& Austin, D. (2013). Enhancing ESL vocabulary development through the use of mobile technology. Journal of Adult Education, 42(1), 1-7.

Oxford, R., \& Crookall, D. (1989). Research on language learning strategies: Methods, findings, and instructional issues. The Modern Language Journal, 73(4), 404-419.

Psaltou-Joycey, A., \& Gavriilidou, Z. (2015). Foreign language learning strategy instruction: A teacher's guide. Kavala: Saita Publications. Accessed May, 30, 2015.

Rabadi, R. I. (2016). Vocabulary learning strategies employed by undergraduate EFL Jordanian students. English Language and Literature Studies, 6(1), 47-58.

Ramos, R., \& Dario, F. (2015). Incidental vocabulary learning in second language acquisition: A literature review. Profile Issues in Teachers Professional Development, 17(1), 157-166. 
Rigney, J. W. (1978). Learning strategies: A theoretical perspective. Learning Strategies, 165205.

Rubin, J. (1975). What the "Good Learner" Can Teach Us* Language. TESOL Quarterly, 9(1), 41-51.

Rubin, J. (1987). Learner strategies: Theoretical assumptions, research history and typology. Learner Strategies in Language Learning, 15-30.

Schmitt, N. (1997). Vocabulary learning strategies. In N. Schmitt \& M. McCarthy (Eds.), Vocabulary: Description, acquisition and pedagogy (pp. 199-227). Cambridge: Cambridge University Press.

Stern, H. H. (1975). What can we learn from the good language learner? Canadian Modern Language Review, 31(4), 304-319.

Stoffer, I. (1995). University foreign language students' choice of vocabulary learning strategies as related to individual difference variables [PhD Thesis]. The University of Alabama.

Tanyer, S., \& Öztürk, Y. (2014). Pre-service English Teachers' Vocabulary Learning Strategy Use and Vocabulary Size: A Cross-sectional Evaluation. Journal of Language Teaching and Research, 37-45.

Tigarajan, D., Yunus, M. M., \& Aziz, A. A. (2016). What Good Language Learners Do to Learn English Language? Journal of Education and Social Sciences, 5(2).

Tılfarlıoğlu, F. F. Y., \& Bozgeyik, Y. (2012). The relationship between vocabulary learning strategies and vocabulary proficiency of English language learners. International Journal of Applied Linguistics and English Literature, 1(2), 91-101.

Yaprak, Z., Hayta, F., \& Yaprak, I. H. (2013). A contrast analysis of language learning and vocabulary learning strategies used by German language and English language learners. Humanities Sciences, 8(4), 349-362.

Zimmerman, B. J. (2002). Becoming a self-regulated learner: An overview. Theory into Practice, 41(2), 64-70.

Zimmerman, B. J. (2008). Investigating self-regulation and motivation: Historical background, methodological developments, and future prospects. American Educational Research Journal, 45(1), 166-183. 